\title{
Adhesive Testing for the BTeV Pixel Detector
}

\author{
C.M. Lei, Simon Kwan, D. Hicks, Eileen Hahn, \\ Jay Hoffman, Sharon Austin, Renee Jones \\ Fermi National Accelerator Laboratory
}

April 19, 2005

\section{Introduction}

The basic unit of the $\mathrm{BTeV}$ pixel detector is a multi-chip module which is comprised of a silicon sensor module bump-bonded to a number of readout chips. The pixel module will then be glued to a high intensity interconnect (HDI) cable using electrically conductive adhesive, and then onto a substrate using another kind of adhesive with reasonable thermal conductivity. This report is mostly addressed to the need of the latter - the substrate adhesive. The aim of this technical note is to summarize the testing efforts and results of this substrate adhesive covering a period since 2001 till the end of 2004.

The substrate will serve two purposes: mechanical support and cooling of the modules. Stresses and strains will be generated when there is a thermal change on the substrate. In addition, since there are many kinds of materials, with different coefficient of thermal expansion (CTE), being glued together to form the complete detector assembly, the substrate may get distorted due to the CTE mismatches. As stress is directly proportional to the material modulus, a significant amount of effort was concentrated in understanding the adhesive modulus. There are other constraints which need to be considered as well. For instance, the detector will be placed in a vacuum close to the beam, and it will be exposed to significant radiation during operation. The requirements of this substrate adhesive can thus be listed as below:

- Curing at room temperature within 24-48 hours

- Operating temperature within $40 \mathrm{C}$ to $-40 \mathrm{C}$ and will remain in a good working condition even if it is exposed to cryogenic temperature

- Low outgassing rate and suitable for use in a vacuum system down to $\times 10^{-8}$ torr

- Radiation hard: can withstand up to $20 \mathrm{Mrad}$ with no degradation in properties

- Soft and compliant: low modulus to minimize the thermal stresses generated due to the Coefficient of Thermal Expansion (CTE) mismatch between silicon module and substrate

- Low ionic impurities within the adhesive to prevent galvanic corrosion from occurring in case that it would be in contact with silicon

- Good wetting properties

- Easy to apply in a uniform thickness

- Not flowing during application: adhesive confined under the module and will not flow over the neighboring module

- No creeping after curing

- Good thermal conductivity to minimize the temperature drop across the adhesive layer

- Low CTE to minimize the thermal strain 
- Good electrical conductivity is preferred

- Re-workable: Possible to allow module repair and replacement without damaging the substrate

- Compatibility with the cooling mechanism used

- Long term stability.

As there are so many requirements on the adhesive, it is certainly not that easy to find one that meets all the demands. With a reasonable screening that the adhesive candidates being radiation hard and have low outgassing, searching for suitable adhesives was focused on those with low modulus. That is because (1) a mechanically reliable and failproof adhesive structure with low stress is needed, and (2) the leaking current characteristics of the modules will increase if mechanical stresses are too high. However, much of the technical information needed is usually not available from the vendor and therefore testing on our own is needed to verify the compliancy.

The demands for good thermal and electrical properties would be lessened in favor of the more important properties if conflicts arose in our decision. As the adhesive layer would be as thin as about $0.05 \mathrm{~mm}$, the temperature drop across it would be small, so a lower number in thermal conductivity would be tolerable. Also, having a greater coefficient of thermal expansion (CTE) value for the adhesive would be acceptable, as long as the modulus is low enough so that high thermal stress would not be generated within the pixel module.

For our testing purposes, some of the samples in these testing groups have been exposed to ionizing radiation. It is known that ionizing radiations incident on organic materials causes the formation of free radicals by rupturing covalent bonds. These radicals are chemically active and can form new bonds, altering the structure of the polymeric material and resulting in changes of its appearance and of the chemical, physical, and mechanical properties. It is thus important that some samples be subjected to ionizing radiation. Mechanical testing should be conducted on a group of samples to ensure that the mechanical properties are still acceptable after heavy radiation dosages. The results of these tests will portray a more accurate idea as to whether the material that will meet the expectations of the experiments in our unique environment.

As our ultimate working temperature for the substrate adhesive is in the range of $-5^{\circ} \mathrm{C}$ to $-20^{\circ} \mathrm{C}$, the mechanical properties at this temperature should be examined as well. Likewise, as adhesive properties may be negatively affected after they go through thermal cycles between room temperature and the lowest foreseeable temperature that the system will be exposed to, the effect of thermal cycles on these mechanical properties have to be checked also. In light of this, some samples were selected and tested after they had gone through such thermal cycle. The cooling system chosen in the BTeV pixel detector is based on liquid nitrogen flowing at the two ends of a substrate made out of thermal pyrolytic graphite (TPG) which has excellent thermal conductivity. While our system design has enough safety features included to prevent the substrates ever to be exposed to cryogenic temperatures, as a precaution, the thermal cycle tests were done from room temperature down to cryogenic temperatures. 
Some of the adhesives we were interested in testing are very expensive. Because of this, tests were done with only a small number of samples. One should realize that the property information reported on the manufactures technical data sheet are typical values only. Large variances in the testing results can be significant even though the testing procedures follow the same ASTM standard. This variation may be due to:

- Polymer molecular weight lot-to-lot variation during manufacturing

- Different surface preparation before testing

- Different human manipulation in metering and mixing the testing adhesive

- Different entrapped-air removal technique

- Different environment control

- Different sensitivity of testing equipment

For all the epoxies studied for our application, as the manufacturers provide no warranty on any listed properties, it is advisable to repeat the tests since our loading and environmental conditions are very different from most other applications. One may expect that the results from our testing will not be identical to the data quoted in the technical data sheet provided by the manufacturers. Moreover our experience shows that the quoted data is usually found to be on the high side anyway, it is always better to perform further testing on new batches of the adhesive material as they are received.

It is noted that there are quite a number of studies on adhesives for silicon detectors and for other HEP experiments. In preparing this note, we have compared or used some of the results obtained from these studies [1-4].

\section{Testing Samples preparation}

All testing samples were prepared in the Fermilab Material Development Laboratory. Adhesives were metered and mixed thoroughly according to the vendor's recommendations. They were then put inside a vacuum bell-jar system in an attempt to remove any entrapped gases. This method was thought to be the best, but due to the high viscosity of some of the samples, some gases remain, trapped, causing voids in the sample. These adhesives were then put into a mold and they were cured according to the general ASTM requirements (40 hours minimum at $23^{\circ} \mathrm{C} \pm 2^{\circ} \mathrm{C}$ and $50 \% \pm 5 \%$ relative humidity). However, for some of the formulations, the adhesive would not get cured properly if an enclosed mold was used. Also, a dog-bone mold, which is the preferred shape of tensile test specimen according to the ASTM method, would consume quite a large amount of volume of adhesive and hence would increase the chance of entrapping more voids. It was because of this a modified sample for tensile test was thus proposed; i.e. a much small quantity of adhesive (1"x0.5” 0.06 ”) was glued between two pieces of brass bars. To prove this concept feasible, a couple of test samples using a general 3M silicon adhesive were made and tested at Fermilab Material Development Laboratory. The results turned out reasonably good so some of the tensile test samples were made in this way. 


\section{Test done by outside contractors}

Some tests were performed by outside companies. We prepared samples of the adhesives and sent them to the contracted laboratories to do the tests. These tests include:

a) Young's modulus

All tests were conducted according to the ASTM standards. The key property that was required was a low Young's modulus. In performing a test to determine the modulus, the other two properties like tensile yield strength, and \% elongation strain at break would be the bonus information if the breakage occurred within the adhesive. As the working temperature of the adhesive is about $-20^{\circ} \mathrm{C}$ and the Fermilab Material Development Laboratory was not equipped with a temperature conditioning chamber in which tensile tests could be done at $-20^{\circ} \mathrm{C}$, all of these low temperature tests were conducted by the outside laboratory - Polymer Diagnostics Inc. (PDI).

Four kinds of samples were pre-conditioned and tested by PDI:

- A - Original unconditioned samples; Tensile tested at ambient temperature

- $\mathrm{B}$ - Conditioned samples at $-17^{\circ} \mathrm{C}$ for 1 month; Tensile tested at $-20^{\circ} \mathrm{C}$

- $\mathrm{C}$ - Thermal cycled samples (between $-196^{\circ} \mathrm{C}$ and $+20^{\circ} \mathrm{C}, 5$ times); Tensile tested at $-20^{\circ} \mathrm{C}$

- D - Irradiated at $10 \mathrm{Mrad}$ and conditioned at $-17^{\circ} \mathrm{C}$ for 1 month samples; Tensile tested at $-20^{\circ} \mathrm{C}$

b) Chemical analysis for Chloride, Phosphorous, Potassium, and Sodium content Silicon is very sensitive to chlorine and potassium ion migration. And it is known that hydrolysable ions such as chlorine $(\mathrm{Cl})$, phosphorus $(\mathrm{P})$, sodium $(\mathrm{Na})$, and potassium $(\mathrm{K})$ can lead to corrosion of aluminum (Al) metal on an IC or silicon sensor. These ionic impurities in an epoxy should be as little as possible and typically should not exceed $50 \mathrm{ppm}$. For $\mathrm{Cl}$ and $\mathrm{P}$, the measurements were made by the colormetric method. For $\mathrm{K}$ and $\mathrm{Na}$, the method used was Atomic Absorption Spectroscopy. Fitzsimmons \& Associates Inc was appointed to do this analysis. Four samples were done, and it was found that NEE001 and AIT EG8050 had the least quantities of ionic impurities while the other two 3M products DP-190EG and 9882 adhesive tape were within acceptable ranges.

4. Tests done by the Fermilab Material Development Laboratory

a) Young's modulus

One extra set of samples using the same batch of epoxy sample production that made for PDI was made and reserved for testing at Fermilab. The same testing standard was followed. In addition, the testing of other adhesives' structural strength was also conducted. 
b) Lap shear test

All tests were conducted at FermiLab according to ASTM D 1002-72 (83). In addition to using aluminum as an adherent as advised by the standard, G10, kapton and silicon were also used because these adherents would meet our application closer. Some samples were first irradiated at 10Mrad gamma and then the tests were repeated to check the irradiation effect.

c) Surface resistivity test

Tests were conducted according to ASTM D 257-78 (83) Standard Test Method for D-C Resistance or Conductance of Insulating Materials. Each epoxy tested was molded in round-RTV molds that were initially weighed and then prior to testing they were dimensionally measured. These tests were performed with a Keithley Programmable Electrometer, Model 617. Each sample was handled with gloves starting from when it was removed from the mold to prevent surface contamination. Once placed in the electrometers environmental chamber the sample was left for 24 hours to allow it to stabilize electrically. Data was then recorded for about one week and then the values were averaged. This number was then used to calculate the resistivity.

d) Outgassing test

Outgassing is the release of gases trapped in a material. Therefore, a larger amount of gas, and hence the pressure, will gradually rise if a piece of material is kept inside a vacuum chamber for a period of time. A test measuring the rate of this gas load rise for a certain size of adhesive surface area for a period of time was performed within an ultra clean vacuum chamber. This method allowed us to determine the adhesive outgassing rate. To minimize the background errors that came from the vacuum chamber wall and its fixture, a small chamber was used to test a large piece of adhesive sample. This test was conducted at the Particle Physic Department, Thin-film Evaporation facility located at Lab 7 within Fermilab.

\section{Finite Element Analysis (FEA)}

Some preliminary FEAs were run using beryllium as the substrate. Beryllium has the worst CTE (11.5 ppm/C) among the choices of substrate being considered. It was verified that the modulus of the adhesive should not be too high. For instance, a regular epoxy like Stycast 2850 with $\mathrm{E}=1.3 \mathrm{Msi}$ and $\mathrm{CTE}=27 \mathrm{ppm} / \mathrm{C}$ was found that it could generate a maximum resultant stress as high as 6,100 psi, and it would significantly exceed the strength of the epoxy. Since the generated stress is directly proportional to the modulus of the material, a low modulus adhesive is thus desirable. If a lower modulus adhesive, like the AIT EG8050 ( $\mathrm{E}=20,000 \mathrm{psi}$, CTE $=120 \mathrm{ppm} / \mathrm{C})$ was selected, the generated stress was found to be greatly reduced and was down to about 350 psi.

More FEAs were run using the much lower modulus NEE001 silicone (E=95 psi), the maximum resultant stress was found to be very small, and it was just about 3 psi. 


\section{Results}

As air entrapment during the sample preparation could not be completely eliminated, the results we obtained somewhat varied. Most the tests that were done at room temperature are tabled in Table 1. In which, the results of Young's modulus are plotted in details with sample sizes in Figures 1 and 2. In particular, the results of the tests conducted by PDI with four different pre-conditions are shown in Table 2 with modulus results plotted in Figure 3 and 4 . The results of impurities are shown in Table 3 while the results of outgassing rates are plotted in Figure 5.

\begin{tabular}{|c|c|c|c|c|c|c|c|c|c|c|c|c|c|c|}
\hline \multirow{3}{*}{$\begin{array}{l}\text { Manufacturer } \\
\text { Brand }\end{array}$} & \multirow{3}{*}{$\begin{array}{l}\text { Data } \\
\text { from }\end{array}$} & \multirow{3}{*}{$\begin{array}{l}\text { Young's } \\
\text { Modulus } \\
\text { psi }\end{array}$} & \multirow{3}{*}{$\begin{array}{l}\text { Yield } \\
\text { Strength } \\
\text { psi }\end{array}$} & \multirow{3}{*}{$\begin{array}{l}\% \text { strain } \\
\text { at break } \\
\%\end{array}$} & \multirow{2}{*}{\multicolumn{4}{|c|}{$\begin{array}{l}\text { Overlap shear Strength } \\
\text { Aluminum adherent } \mathrm{G}-10 \text { adherent }\end{array}$}} & \multirow{3}{*}{$\begin{array}{l}\text { Surface } \\
\text { Resistivity } \\
\text { ohm"m }\end{array}$} & \multicolumn{2}{|c|}{ Impurities } & \multirow{3}{*}{$\frac{\mathrm{K}}{\mathrm{ppm}}$} & \multirow{3}{*}{$\frac{\mathrm{Na}}{\mathrm{ppm}}$} & \multirow{3}{*}{$\begin{array}{l}\text { Outgassing } \\
\text { Rate } \\
\text { torr" } / \mathrm{s} / \mathrm{cm}^{*} 2\end{array}$} \\
\hline & & & & & & & & & & \multirow{2}{*}{\begin{tabular}{|l|}
$\mathrm{Cl}$ \\
$\mathrm{ppm}$
\end{tabular}} & \multirow{2}{*}{$\frac{P}{p p m}$} & & & \\
\hline & & & & & psi & psi & psi & psi & & & & & & \\
\hline & & & & & & irradiated & & irradiated & & & & & & \\
\hline $3 \mathrm{M}$ & Vendor & & & & 1,700 & & & & $3.0 E+12$ & & & & & \\
\hline 2216 translucent & FermiLab & 1,007 & 1,231 & & 1,178 & & 1,137 & & $7.4 \mathrm{E}+14$ & & & & & $1.70 \mathrm{E}-08$ \\
\hline $3 M$ & Vendor & 145 & & & 70 & & & & & $<10$ & $<10$ & $7.50 E+00$ & 29 & \\
\hline 9882 tape & Fermilab & 74 & 83 & $141 \%$ & 29 & 51 & 40 & 88 & & & & & & $2.00 \mathrm{E}-06$ \\
\hline $3 \mathrm{M}$ & Vendor & 39,000 & 2,750 & $120 \%$ & & & & & & $<5$ & $<5$ & $3.55 E+01$ & 13 & \\
\hline DP $190 E G$ & FermiLab & 32,000 & 1,214 & $6.10 \%$ & & & & & $4.7 E+08$ & & & & & \\
\hline Bacon Industry & Vendor & $1,600,000$ & & & & & & & $1.0 \mathrm{E}+12$ & & & & & \\
\hline LCA 4LV-BA5 & FermiLab & & & & $1040 \dagger$ & $487 \dagger$ & $198 t$ & $173 t$ & $1.6 \mathrm{E}+16$ & & & & & \\
\hline Dexter Hysol & Vendor & $6.15 E+05$ & & & 6675 & & & & $4.6 \mathrm{E}+13$ & & & & & \\
\hline \multirow[t]{2}{*}{ EA 9394} & Cern & $2,291,000$ & & $0.310 \%$ & 1,508 & 1,378 & & & & & & & & \\
\hline & Fermilab & & & & 3,000 & & & & $8.90 E+15$ & & & & & $7.90 E-09$ \\
\hline Emerson Cuming & Vendor & & & & 8,400 & & & & $5.0 \mathrm{E}+16$ & & & & & \\
\hline \multicolumn{2}{|c|}{ Stycast 2850FT 24L PDI } & $1,729,139$ & 7,500 & $0.41 \%$ & & & & & & & & & & \\
\hline & Cern & $2,624,500$ & & $0.33 \%$ & 1,842 & 1,929 & & & & & & & & \\
\hline & Fermilab & $1,054,800$ & 4,700 & $0.77 \%$ & & & 158 & & & & & & & \\
\hline Hexcel & Vendor & & 8,500 & & 3,000 & & & & & $<5$ & 22 & $1.60 E+00$ & 8 & \\
\hline Epolite 5313 & Fermilab & 29,845 & 2,063 & & & & 2,063 & & $7.0 \mathrm{E}+15$ & & & & & $8.25 E-10$ \\
\hline Al Tech & Vendor & 20,000 & 1,400 & & 1,000 & & & & 4.0E-02 & N/A & N/A & $3.50 E+00$ & 7.3 & \\
\hline EG8050 & FermiLab & 110,000 & 461 & $0.530 \%$ & & & & & 8.60 & & & & & \\
\hline Tra-Con & PDI & $1,244,968$ & 3,930 & $0.59 \%$ & & & & & & & & & & \\
\hline Tra-bond $816 \mathrm{H} 01$ & FermiLab & & & & $310 \dagger$ & & & & $1.3 E+11$ & & & & & \\
\hline Tra-Con & PDI & $1,729,139$ & 7,500 & $0.76 \%$ & & & & & & & & & & \\
\hline Tra-bond 2151 & Fermilab & & & & & & & & & & & & & \\
\hline Masterbond & Vendor & 72,000 & 1,500 & & & & & & & & & & & \\
\hline \multirow[t]{2}{*}{ EP21 TCHT } & PDI & $1,161,136$ & 4,180 & $0.62 \%$ & & & & & & & & & & \\
\hline & Fermilab & $1,160,000$ & 2,615 & $0.62 \%$ & & & & & & & & & & \\
\hline Peltier-Technik & Cern & 174 & & $5 \%$ & 363 & 464 & 363 & 464 & & $<5$ & $<5$ & $6.40 E+00$ & 9 & \\
\hline \multirow[t]{2}{*}{ NEE001 } & PDI & 250 & 150 & $120 \%$ & & & & & & & & & & \\
\hline & FermiLab & 290 & 71 & $195 \%$ & 274 & & $185 \ddagger$ & $23.56 \pm$ & $2.4 E+17$ & & & & & $1.70 \mathrm{E}-09$ \\
\hline
\end{tabular}

Table 1. Results obtained at room temperature 


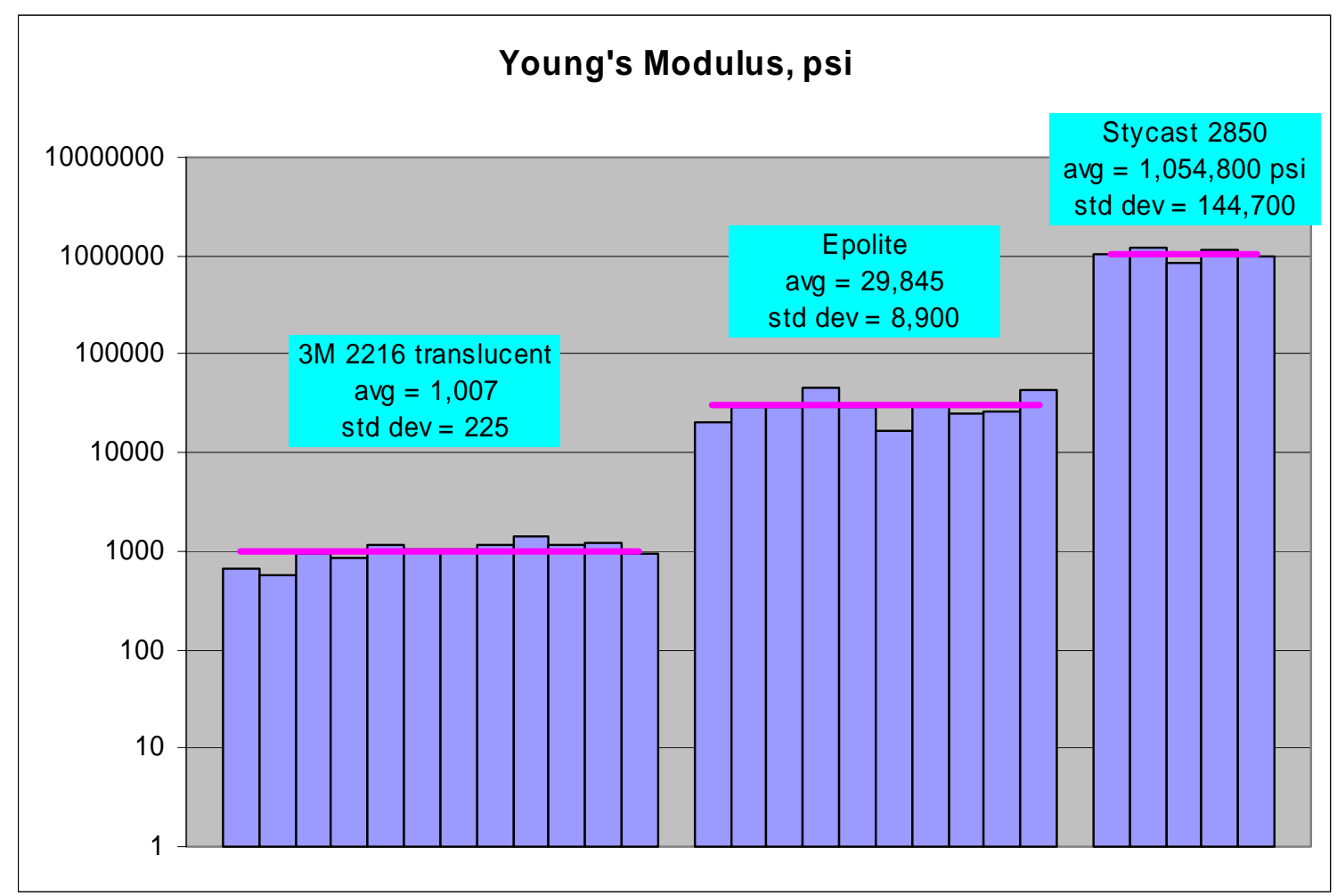

Figure 1. Adhesive Young's Modulus

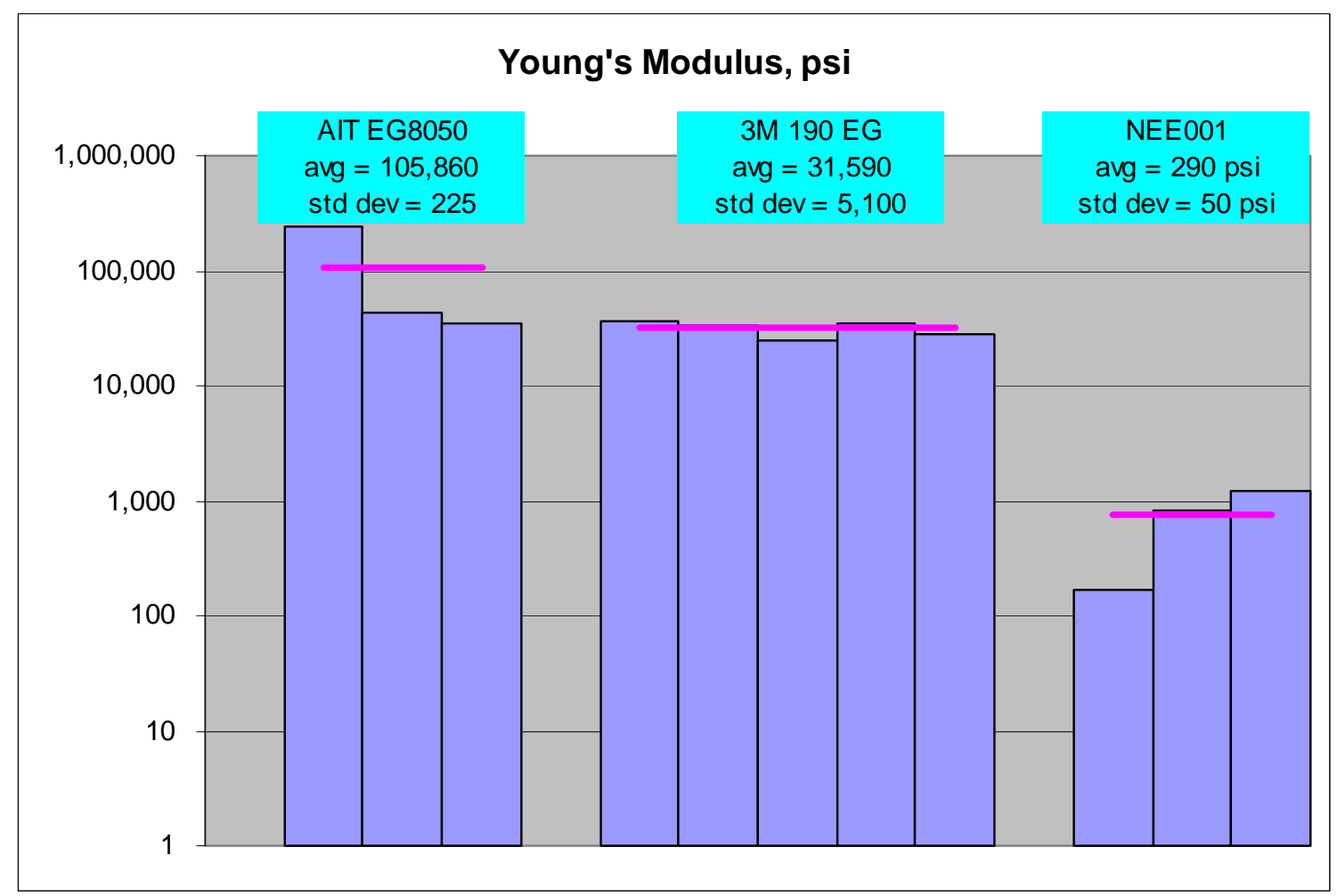

Figure 2. Adhesive Young's Modulus (continued) 
Young's Modulus, PSI

\begin{tabular}{|c|c|c|c|c|}
\hline & $\begin{array}{c}\mathrm{A} \\
\text { Ref }\end{array}$ & $\begin{array}{c}\mathrm{B} \\
-20^{\circ} \mathrm{C}\end{array}$ & $\begin{array}{c}\mathrm{C} \\
\text { Thermal-cycled }\end{array}$ & $\begin{array}{c}\mathrm{D} \\
\text { irradiated }\end{array}$ \\
\hline Tested at & $\mathrm{RT}$ & $-20^{\circ} \mathrm{C}$ & $-20^{\circ} \mathrm{C}$ & $-20^{\circ} \mathrm{C}$ \\
\hline $\begin{array}{c}\text { EP37- } \\
\text { 3FLF }\end{array}$ & 240 & 185,000 & 181,000 & 181,000 \\
\hline NEE001 & 250 & 430 & 380 & 740 \\
\hline
\end{tabular}

\begin{tabular}{|c|c|c|c|c|}
\hline & $\begin{array}{c}\text { A } \\
\text { Ref }\end{array}$ & $\begin{array}{c}\text { B } \\
-20^{\circ} \mathrm{C}\end{array}$ & $\begin{array}{c}\mathrm{C} \\
\text { Thermal-cycled }\end{array}$ & $\begin{array}{c}\mathrm{D} \\
\text { irradiated }\end{array}$ \\
\hline Tested at & RT & $-20^{\circ} \mathrm{C}$ & $-20^{\circ} \mathrm{C}$ & $-20^{\circ} \mathrm{C}$ \\
\hline EP37-3FLF & 60 & 1 & 2 & 2 \\
\hline NEE001 & 120 & 100 & 100 & 50 \\
\hline
\end{tabular}

Tensile Strength, PSI

\begin{tabular}{|c|c|c|c|c|}
\hline & $\begin{array}{c}\mathrm{A} \\
\text { Ref }\end{array}$ & $\begin{array}{c}\mathrm{B} \\
-20^{\circ} \mathrm{C}\end{array}$ & $\begin{array}{c}\mathrm{C} \\
\text { Thermal-cycled }\end{array}$ & $\begin{array}{c}\mathrm{D} \\
\text { irradiated }\end{array}$ \\
\hline Tested at & $\mathrm{RT}$ & $-20^{\circ} \mathrm{C}$ & $-20^{\circ} \mathrm{C}$ & $-20^{\circ} \mathrm{C}$ \\
\hline $\begin{array}{c}\text { EP37- } \\
\text { 3FLF }\end{array}$ & 99 & 3,290 & 2,620 & 3,225 \\
\hline \hline NEE001 & 150 & 186 & 176 & 137 \\
\hline
\end{tabular}

Table 2. Results obtained at $-20^{\circ} \mathrm{C}$ 


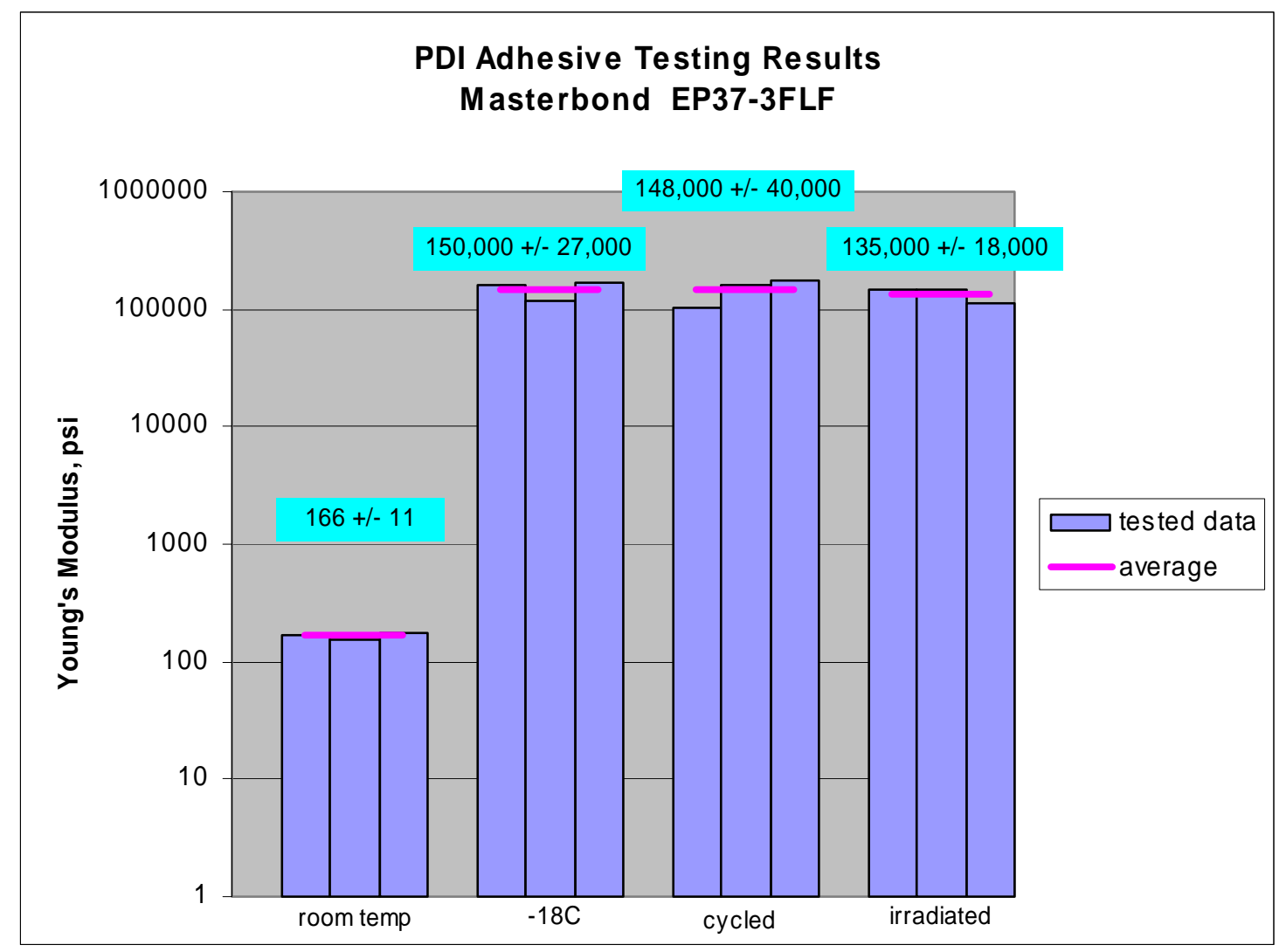

Figure 3. PDI Adhesive Testing at four different Pre-conditions for EP37-3FLF

Impurities within Adhesives, ppm

\begin{tabular}{|c|r|r|r|r|}
\hline & $\mathrm{Cl}$ & $\mathrm{P}$ & $\mathrm{K}$ & $\mathrm{Na}$ \\
\hline 3M 9882 & $<10$ & $<10$ & 7.5 & 29.4 \\
\hline 3M DP190EG & $<5$ & $<5$ & 35.5 & 13.3 \\
\hline Hexcel Epolite 5313 & $<5$ & 22 & 1.6 & 8 \\
\hline Al Tech EG8050 & N/A & N/A & 3.5 & 7.3 \\
\hline
\end{tabular}

Table 3. Impurity testing results 


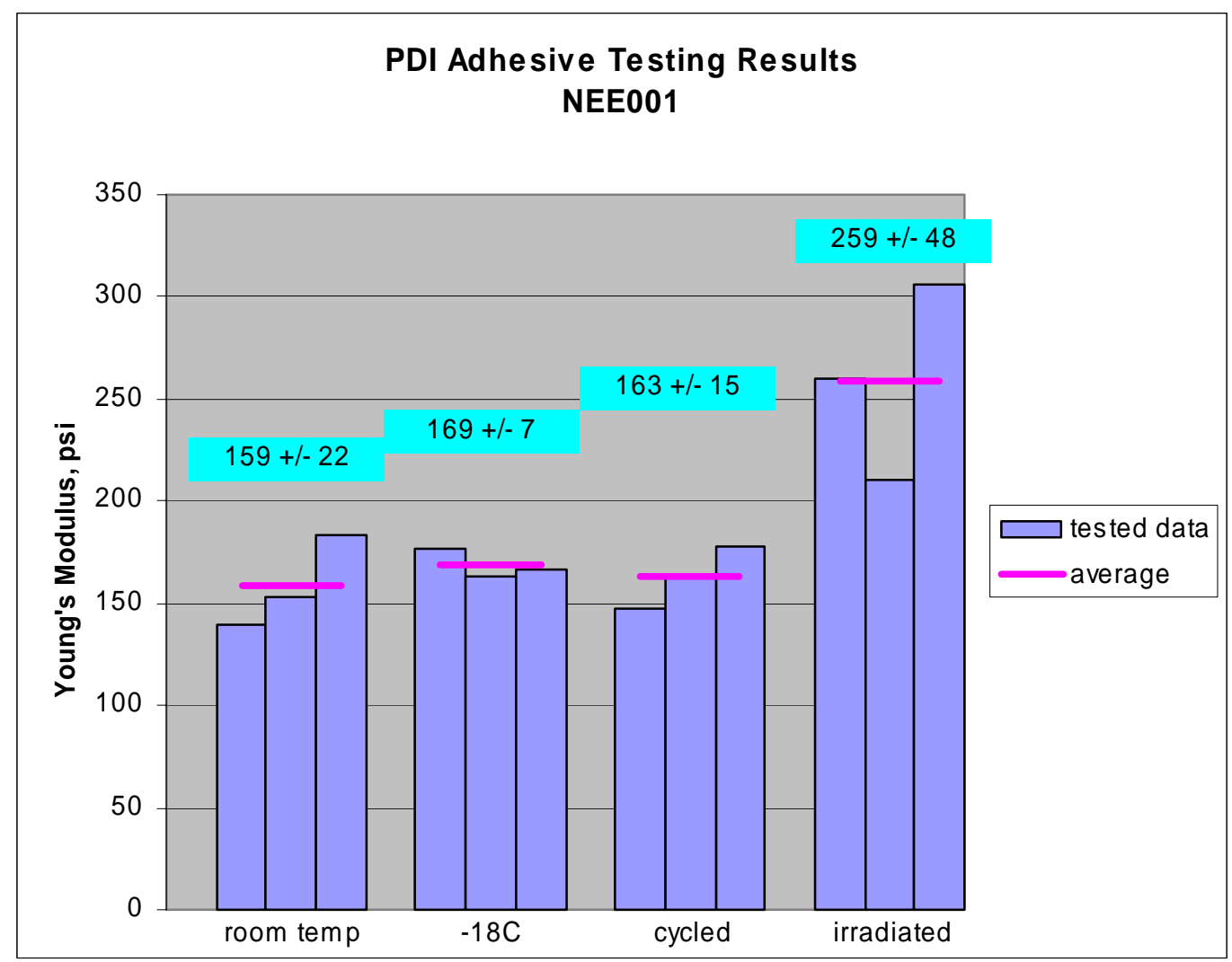

Figure 4. PDI Adhesive Testing at four different Pre-conditions for NEE001

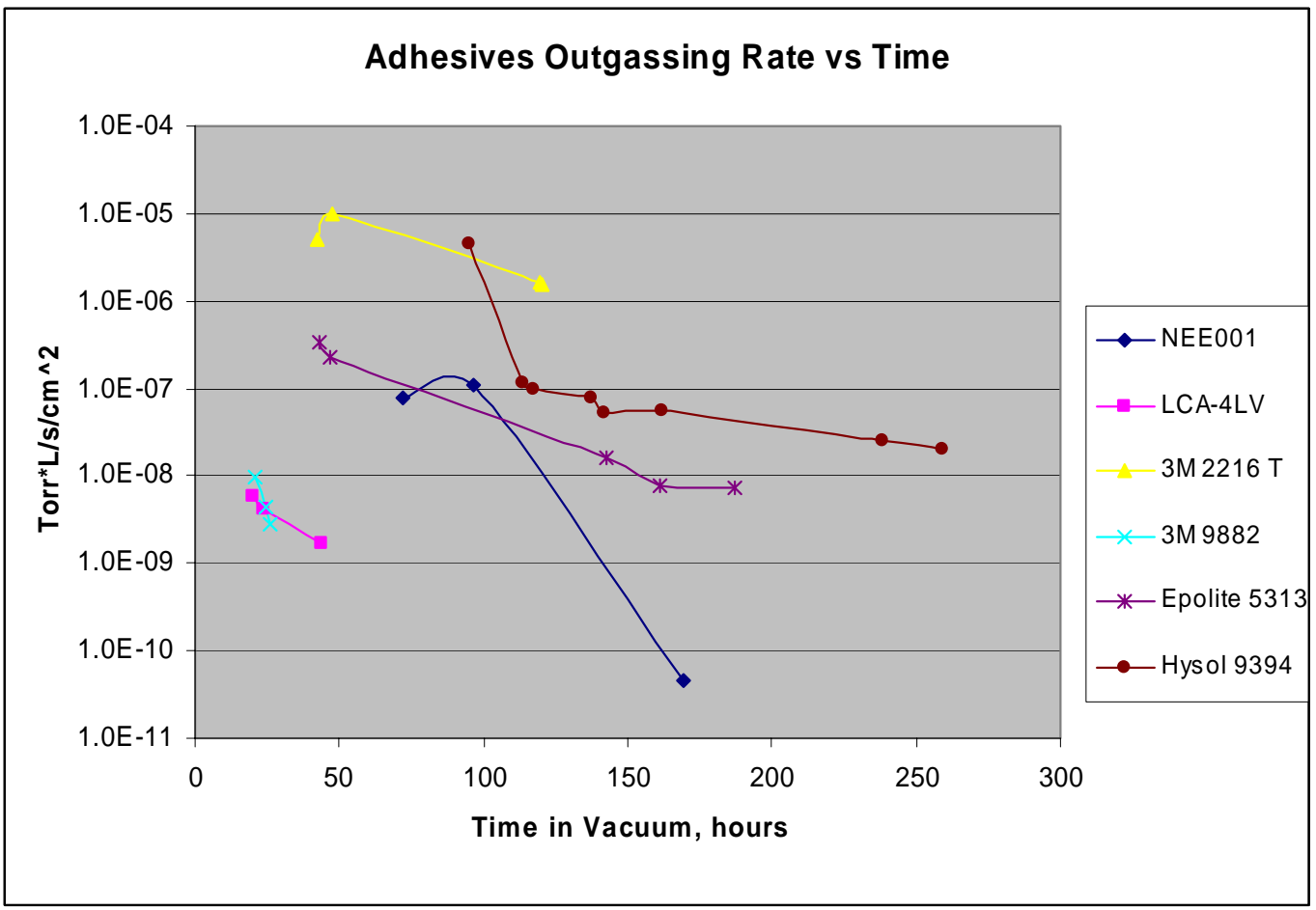

Figure 5. Adhesive Outgassing Rate vs Time 


\section{Summary}

This report basically addressed the mechanical property needs of BTeV. We attempted to find an adhesive that is compliant and flexible down to $-20^{\circ} \mathrm{C}$. Samples were thermallycycled between room temperature and $80 \mathrm{~K}$, and also irradiated at $10 \mathrm{Mrad}$. We present all the test results obtained for various epoxies.

\section{Reference:}

[1]: Iris Abt et al., “Gluing Silicon with Silicone”, Nuclear Instrum. \& Methods A411 (1998), 1901-196.

[2]: A.G. Kholodenko et al., "The thermal and mechanical properties of glues for SCT ATLAS modules assembly”. http://wwwatlas.mppmu.mpg.de/atlas_sct/glue_tst.ps

[3]: CERN Yellow Report 2001-008

[4]: Irving Skeist, Handbook of Adhesives 